\title{
Sustained Virologic Response
}

National Cancer Institute

\section{Source}

National Cancer Institute. Sustained Virologic Response. NCI Thesaurus. Code C120598.

A finding of aviremia at a predetermined time point after the end of planned or actual treatment. 